\title{
Application of hydroxyapatite nanoparticle-assembled powder using basic fibroblast growth factor as a pulp-capping agent
}

\author{
Kazuki IMURA ${ }^{1}$, Yoshiya HASHIMOTO², Masahiro OKADA², Kazushi YOSHIKAWA ${ }^{1}$ and Kazuyo YAMAMOTO ${ }^{1}$ \\ ${ }^{1}$ Department of Operative Dentistry, Osaka Dental University, 8-1 Kuzuhahanazono-cho, Hirakata-shi, Osaka 573-1121, Japan \\ ${ }^{2}$ Department of Biomaterials, Osaka Dental University, 8-1 Kuzuhahanazono-cho, Hirakata-shi, Osaka 573-1121, Japan \\ ${ }^{3}$ Department of Biomaterials, Graduate School of Medicine, Dentistry and Pharmaceutical Sciences, Okayama University, 2-5-1 Shikata-cho, Kita-ku, \\ Okayama 700-8558, Japan \\ Corresponding author, Yoshiya HASHIMOTO; E-mail: yoshiya@cc.osaka-dent.ac.jp
}

\begin{abstract}
We have previously fabricated hydroxyapatite (HAP) nanoparticle-assembled powder (nano-HAP) plates and granules by assembling low-crystallinity HAP nanoparticles without template/binder molecules or high-temperature/pressure treatments. In this study, we combined the nano-HAP with fibroblast growth factor (FGF) 2, which promotes odontoblast differentiation, and used this as a pulpcapping agent for dentin defects created in rat molars. The tissue response was then radiologically and histologically assessed at 1 and 2 weeks after capping, to assess the biocompatibility and ability of this material to promote hard tissue formation. The application of nano-HAP/FGF2 induced the invasion of dental pulp cells and vessels, and was consistently found to stimulate formation of a dentinal bridge containing numerous dentinal tubules. We thus succeeded in treating the pulp exposure by using a physiological approach to promote tissue regeneration. Further investigations should be performed to explain exactly how the nano-HAP/FGF2 combination contributes to calcified tissue formation.
\end{abstract}

Keywords: Basic fibroblast growth factor, Hydroxyapatite, Nanoparticle-assembled powder, Pulp-capping agent

\section{INTRODUCTION}

Calcium hydroxide $(\mathrm{CH})$ is a conventional pulp capping material. $\mathrm{CH}$ has a high $\mathrm{pH}$, and its dental use relates chiefly to its ability to stimulate mineralization, and its antibacterial properties ${ }^{1}$. Numerous studies have shown that $\mathrm{CH}$ is extremely toxic to cells in tissue culture ${ }^{2,3)}$, and thus its use carries a risk of pulp morbidity and apical lesions ${ }^{4}$.

Dental pulp tissue has recently been demonstrated to include a population of putative postnatal stem cells ${ }^{5-8}$. In fact, cultured dental pulp cells are able to induce cell-associated matrix calcification in vitro, which is regulated by various types of cytokines ${ }^{9-11}$, suggesting that cytokines induce regeneration of the injured dentinpulp complex. Among these cytokines, fibroblast growth factor (FGF) 2 plays an important role in the early phase of wound repair by influencing proliferation, homing, and migration of healthy and inflamed dental pulp cells ${ }^{12,13)}$, and production of extracellular matrix components. FGF2 has also been shown to induce vascular invasion and upregulate the expression of the embryonic stem cell markers in dental pulp cells ${ }^{14)}$. Additionally, Sagomonyants et $a l .{ }^{15}$ ) demonstrated that early and limited exposure of pulp cells to FGF2 alone promotes odontoblast differentiation; this has implications for application of FGF2 in dentin regeneration.

Calcium phosphate biomaterials — such as hydroxyapatite (HAP) — has been extensively used for hard tissue replacement and augmentation due to its

Color figures can be viewed in the online issue, which is available at J-STAGE.

Received Jun 14, 2018: Accepted Nov 12, 2018

doi:10.4012/dmj.2018-198 JOI JST.JSTAGE/dmj/2018-198 biocompatibility and osteoconductive potential ${ }^{16-18}$. HAP has also been used for capping vital exposed pulp tissue, as a substitute for $\mathrm{CH}^{19,20)}$. Nano-sized HAP ceramics promote biological activity, as compared to conventional HAP ceramics ${ }^{21-25)}$. In our previous preliminary study ${ }^{26,27)}$, we prepared nanoparticle-assembled plates, which consist of low-crystallinity HAP, by drying an aqueous dispersion of HAP, without template/binder molecules or high-temperature/pressure treatments, and obtained a relatively transparent material that contained nanopores.

In this study, we combined the HAP nanoparticleassembled powder (nano-HAP) with FGF2 and applied this to the exposed dental pulp of rat molars, and then examined the tissue response radiologically and histologically, to assess the biocompatibility of this pulpcapping material and its ability to promote hard tissue formation.

\section{MATERIALS AND METHODS}

\section{Materials used}

Unless otherwise stated, all materials were guaranteed reagent grade and were used as received from Wako Pure Chemical Industries (Osaka, Japan). HAP nanoparticles were prepared using a wet precipitation method ${ }^{26)}$. Briefly, an aqueous solution of $\left(\mathrm{NH}_{4}\right)_{2} \mathrm{HPO}_{4}$ was added to an aqueous solution of $\mathrm{Ca}\left(\mathrm{NO}_{3}\right)_{2} \cdot \mathrm{H}_{2} \mathrm{O}$ (initial $\mathrm{pH}$ 10). HAP nanoparticle-assembled blocks were then prepared by drying the aqueous dispersion of HAP nanoparticles (ca. $4 \mathrm{wt} \%)$ on a polytetrafluoroethylene dish at $60^{\circ} \mathrm{C}$ for $24 \mathrm{~h}$. Nano-HAP particles of approximately 30 
$\mu \mathrm{m}$ in diameter were obtained by grinding the HAP nanoparticle-assembled plates.

\section{Characterization of nano-HAP particles}

A field emission-scanning electron microscope (FESEM; S-4800, Hitachi High Technologies, Tokyo, Japan) was used to analyze particle size and outer surface conditions. Before observation, samples were coated with platinum and palladium using E-1030 (Hitachi High Technologies).

Nano-HAP particles were characterized using the powder X-ray diffraction system (XRD; XRD-6100, Shimadzu, Kyoto, Japan). XRD patterns were obtained under the following conditions: $40.0 \mathrm{kV}, 30.0 \mathrm{~mA}$, scan rate of 2 degrees/min with a step size of 0.05 degrees, over 3-80 degrees. The crystal phase was identified using the database from the International Center for Diffraction Data. Fourier-transform infrared (FT-IR) spectra were obtained using a Spectrum One (PerkinElmer, Waltham, MA, USA), equipped with a diffuse reflectance unit, at a resolution of $4 \mathrm{~cm}^{-1}$, with 16 scans. The HAP nanoparticle-assembled plates were analyzed over a range of 3,600 to $500 \mathrm{~cm}^{-1}$ with $4 \mathrm{~cm}^{-1}$ resolution.

\section{Surface modification of HAP nano-HAP}

FGF2 (Fiblast Spray, Kaken Pharmaceutical, Tokyo, Japan) was immobilized on the nano-HAP particles by immersing the nano-HAP particles in an FGF2 solution $\left(1 \mathrm{mg} / \mathrm{mL}\right.$, in distilled water) for $24 \mathrm{~h}$ at $4^{\circ} \mathrm{C}$ (nanoHAP/FGF2). The procedure was performed in a sterile environment. The elemental composition of the nanoHAP particles was evaluated by X-ray photoelectron spectroscopy (XPS; Ulvac-Phi, Kanagawa, Japan).

\section{Surgical procedure}

All procedures in this study were approved by the Animal Experiment Committee of Osaka Dental University and conformed to the guidelines described in the Guiding Principles for the Use of Laboratory Animals (approval no. 1702012). Bilateral first and second molars of 16 Wistar ST rats (7-week-old males, weighing 200-250 g) were used for these investigations. The rats were on a diet that included solid food (MF, Oriental Yeast, Tokyo, Japan) and water freely available in their cages, which were located in the animal research center affiliated with our university. A mixture of three types of anesthetic agents, medetomidine $1 \mathrm{mg} / \mathrm{mL}$ (Domitor, Nippon Zenyaku Kogyo, Tokyo, Japan), midazolam $5 \mathrm{mg} / \mathrm{mL}$ (Midazolam, Sandoz, Princeton, NJ, USA), butorphanol $5 \mathrm{mg} / \mathrm{mL}$ (Butorphanol, Meiji Seika Pharma, Tokyo, Japan), was injected (0.5 mL/100 g body weight) into the rats prior to pulpotomy and capping. Pulpotomy was performed using No. 1/2 round diamond points, under water irrigation, according to standard clinical procedures. After pulpotomy, irrigation was performed by alternately using NaOCI (NeoCleaner, Neo Seiyaku, Nagoya, Japan) and 3\% EDTA solution (Smearclean, Nippon Shika Yakuhin, Tokyo, Japan), and after confirming hemostasis by lightly applying a sterilized cotton ball, the wound surface of the sectioned pulp was capped with nano-HAP (nano-HAP group) or with the nano-HAP/FGF2 complex (nano-HAP/FGF2 group). After pulp capping, cavities were prepared and filled with 4-META/MMA-TBB resin (Super-Bond, Sun Medical, Shiga, Japan). Eight molars were used per time period and per group. Teeth on one side were treated with nano-HAP or with the nano-HAP/FGF2 complex, and those on the other side were only preliminarily sealed with Super-Bond after pulpotomy, as a control.

Micro-computed tomography (Micro-CT) imaging of animal specimens

At the end of the observation period (1 and 2 weeks after surgery), the animals were euthanized by lethal exsanguination under intravenous anesthesia with sodium pentobarbital. A micro-CT scanner voltage and current were set at $70 \mathrm{kV}$ and $70 \mathrm{~mA}$, respectively, with no aluminum filter in place, and images were obtained of the treated teeth. The slice thickness was set at $25 \mu \mathrm{m}$. Serial coronally oriented tomograms were reconstructed from the raw images. High-resolution three-dimensional (3D) images were constructed using the TRI/3D bone software (Ratoc, Tokyo, Japan).

\section{Histological analysis}

After fixation, the samples were decalcified, dehydrated, and embedded in paraffin. The specimens were sectioned at 5 - $\mu \mathrm{m}$ thickness and used for hematoxylin-eosin staining (H-E staining).

To detect vascularization by immunostaining, deparaffinized, rehydrated sections were treated with $0.1 \%$ trypsin, and vascular endothelial cells were labeled using a monoclonal anti-human von Willebrand Factor (vWF) antibody at a final dilution of 1:1000 (Abcam, Cambridge, UK; ab6994). Immunoreactivity was detected using the EnVision system (Dako, Tokyo, Japan; K4003). Sections were visualized under a BZ9000 All-in-One Fluorescence Microscope (Keyence, Tokyo, Japan).

\section{RESULTS}

\section{Scanning electron microscopy (SEM) observation}

SEM revealed that the nano-HAP consisted of spherical nanoparticles with a diameter of approximately $30 \mathrm{~nm}$, and nanosized pores were also observed between the nanoparticles (Fig. 1).

\section{XRD measurement}

The XRD measurement showed a broad pattern of HAP (JCPDS No. 9-732), and no other calcium phosphate phases could be detected (Fig. 2).

\section{FT-IR spectrum analysis}

The FT-IR spectrum of the nano-HAP is shown in Fig. 3. The absorption bands at $601 / 562$ and $472 \mathrm{~cm}^{-1}$ are attributed to $v_{4} \mathrm{PO}_{4}{ }^{3-}$ and $v_{2} \mathrm{PO}_{4}{ }^{3-}$, respectively, in HAP. The absorptions at 1,090/1,026 and $963 \mathrm{~cm}^{-1}$ are attributed to $v_{3} \mathrm{PO}_{4}{ }^{3-}$ and $v_{1} \mathrm{PO}_{4}{ }^{3-}$, respectively. The absorption of $\mathrm{OH}\left(3,544\right.$ and $\left.631 \mathrm{~cm}^{-1}\right)$ in crystalline 

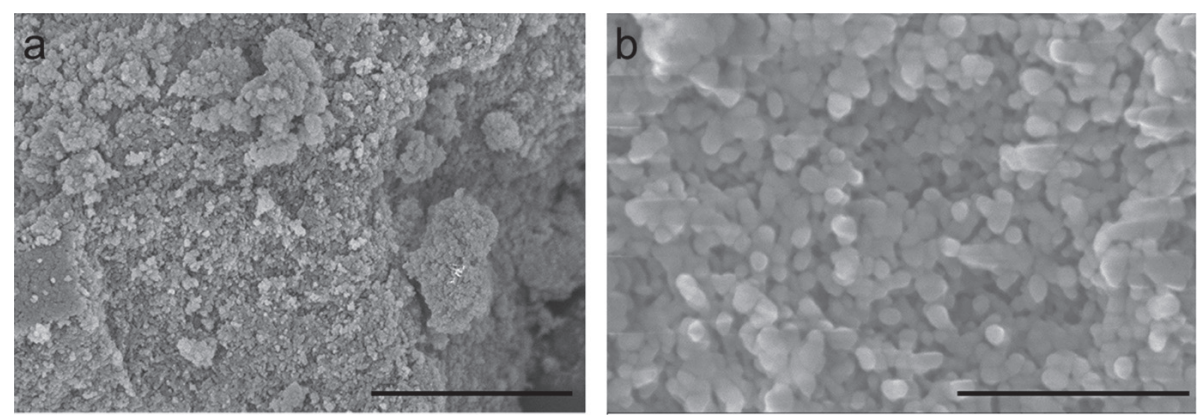

Fig. 1 SEM observations of the surfaces of nano-HAP.

Bars $\mathrm{a}=2 \mu \mathrm{m}$, Bars $\mathrm{b}=500 \mathrm{~nm}$ (a: Low magnification b: High magnification).

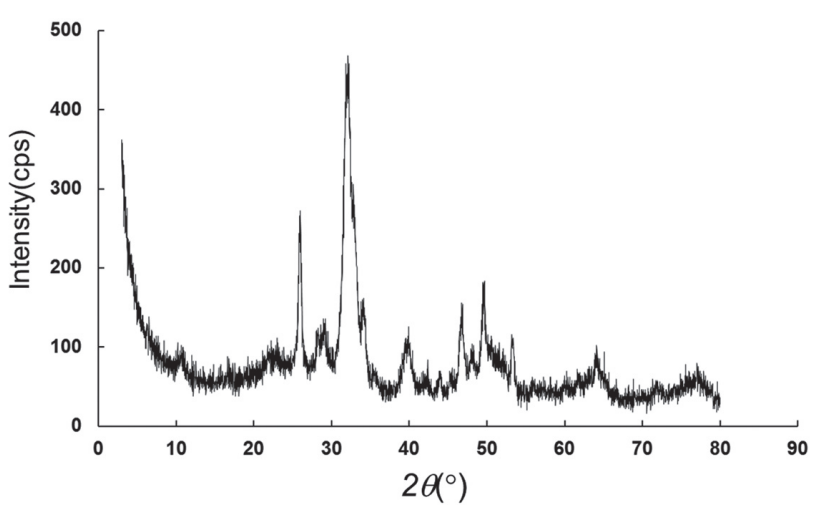

Fig. 2 X-ray diffraction patterns of the nano-HAP.

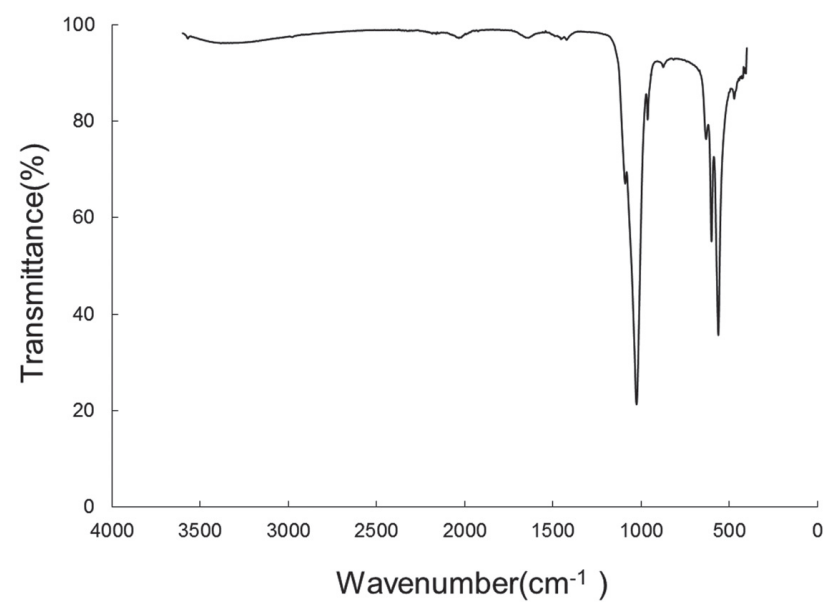

Fig. 3 FT-IR spectra of the nano-HAP.

HAP $^{28,29)}$ was weak, which also indicates that the nanoHAP exhibits low crystallinity. Peaks at 1,454/1,422 and $874 \mathrm{~cm}^{-1}$ were are attributed to $\mathrm{CO}_{3}{ }^{2-}$ substituted with $\mathrm{PO}_{4}^{3}$.

\section{XPS analysis}

The $\mathrm{Ca} / \mathrm{P}$ atomic ratio of the powder measured by XPS

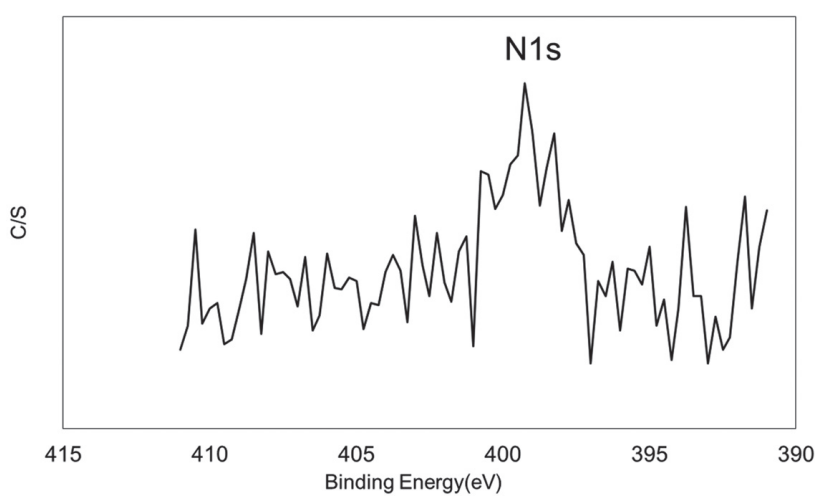

Fig. 4 Surface characterization of FGF2 bound to HAP assembled nanoparticles.

was 1.45, suggesting that the surface of the powder was calcium-deficient. A small nitrogen peak (N1 s) corresponding to FGF2 was detected by XPS analysis of FGF2 bound to nano-HAP particles (Fig. 4).

\section{$3 D$ pseudo-color images}

Micro-CT cross-sectional images of 3D pseudo-color representations of mineral density are shown in Figs. 5 and 6. Warmer colors (red, yellow) denote high mineral density, while cooler colors (blue, green) indicate low mineral density. The newly formed dentin indicated low mineral density in cooler colors in both the nano-HAPs and nano-HAP/FGF2 groups at weeks 1 and 2, but not in the control group (Figs. 5 and 6).

\section{Histological analysis}

1. One week after surgery

In the control group, precipitation of fibrin was observed at the surface of the exposed pulp. Restorative dentin was slightly and irregularly formed on the original dentinal wall, from the surface of the pulp to the pulp chamber (Figs. 7a, c). In the nano-HAP group, odontoblast-like cells and a layer of thin reparative dentin was also observed, from the original dentin to the dental pulp (Figs. 7b, e). In the nano-HAP/FGF2 group, a necrotic layer was observed immediately below the pulp exposure. 

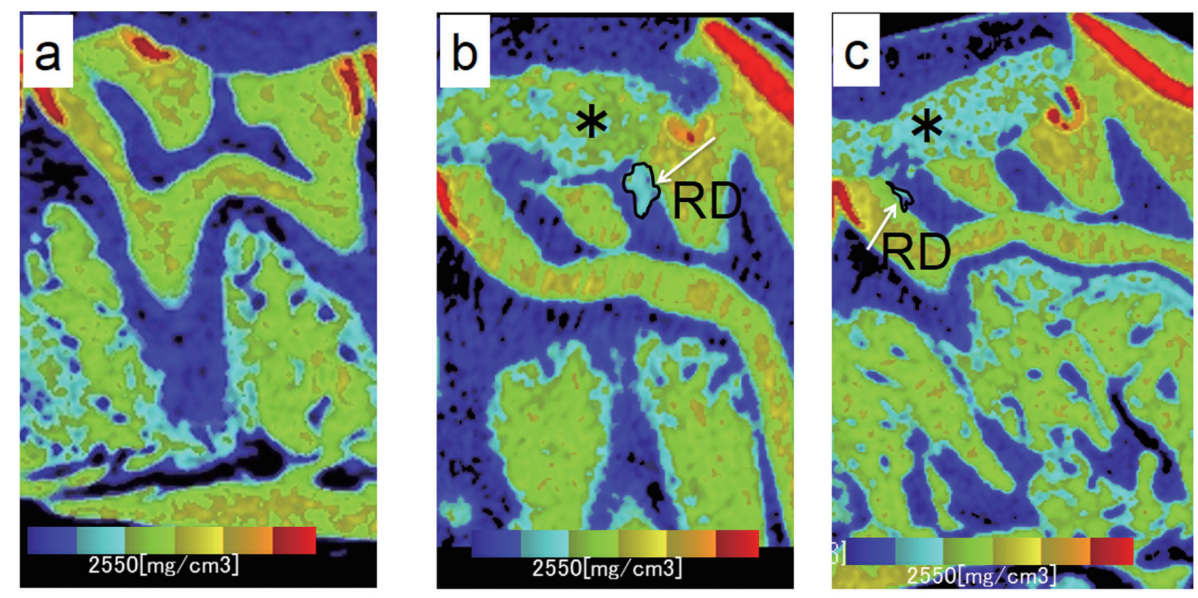

Fig. 5 Micro-CT cross-sectional images of 3D pseudo-color representations of the mineral density at 1 week after surgery. a: Control group. b: Nano-HAP group, c: nano-HAP/FGF2 group, RD: reparative dentin.
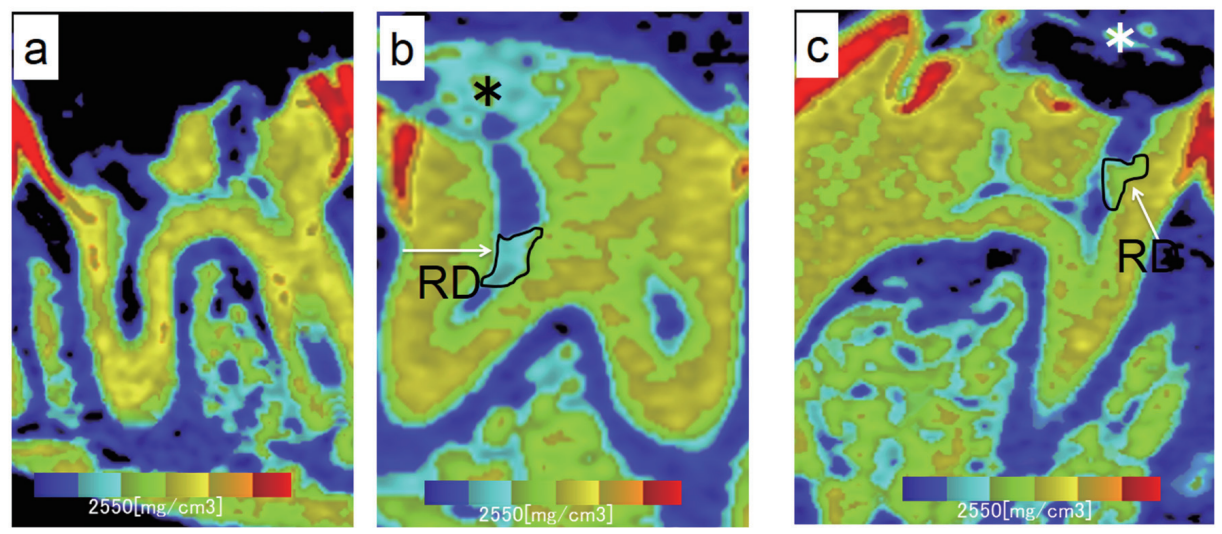

Fig. 6 Micro-CT cross-sectional images of 3D pseudo-color representations of mineral density at 2 weeks after surgery.

a: Control group, b: Nano-HAP group, c: nano-HAP/FGF2 group, RD: reparative dentin.

Although cellular components were abundant in the coronal pulp from immediately below the necrotic layer to the pulp chamber, some odontoblasts were observed to be arranged close to the reparative dentin (Figs. 7c, f). In the nano-HAP/FGF2 group, vascular endothelial cells, stained by the vWF antibody, were prominent in the pulp exposure (Fig. 8c).

\section{Two weeks after surgery}

In the control group, fibrin was precipitated from the surface of the pulp exposure at 2 weeks after surgery. Although some new dentin formation was observed, no marked change was observed as compared with the image taken at 1 week after surgery (Figs. 9a, d). In the nano-HAP group, the invasion of numerous inflammatory cells was observed. Although the exposed pulp was not yet closed, formation of reparative dentin was observed below the pulp exposure (Figs. 9b, e). In the nano-HAP/ FGF2 group, dental pulp tissues increased from the surface of the pulp exposure, and reparative dentin with a cortical bone structure had irregularly formed from the original dentin wall. Dentinal bridge-like calcified tissue, containing numerous dentinal tubes, was observed in the dentin defect area. The orientation of these dentinal tubules was different from that of the original dentinal tubules (Figs. 9c, f). In the control and the nano-HAP groups, vascular endothelial cells were observed in the pulp exposure area (Figs. 8d, e). 


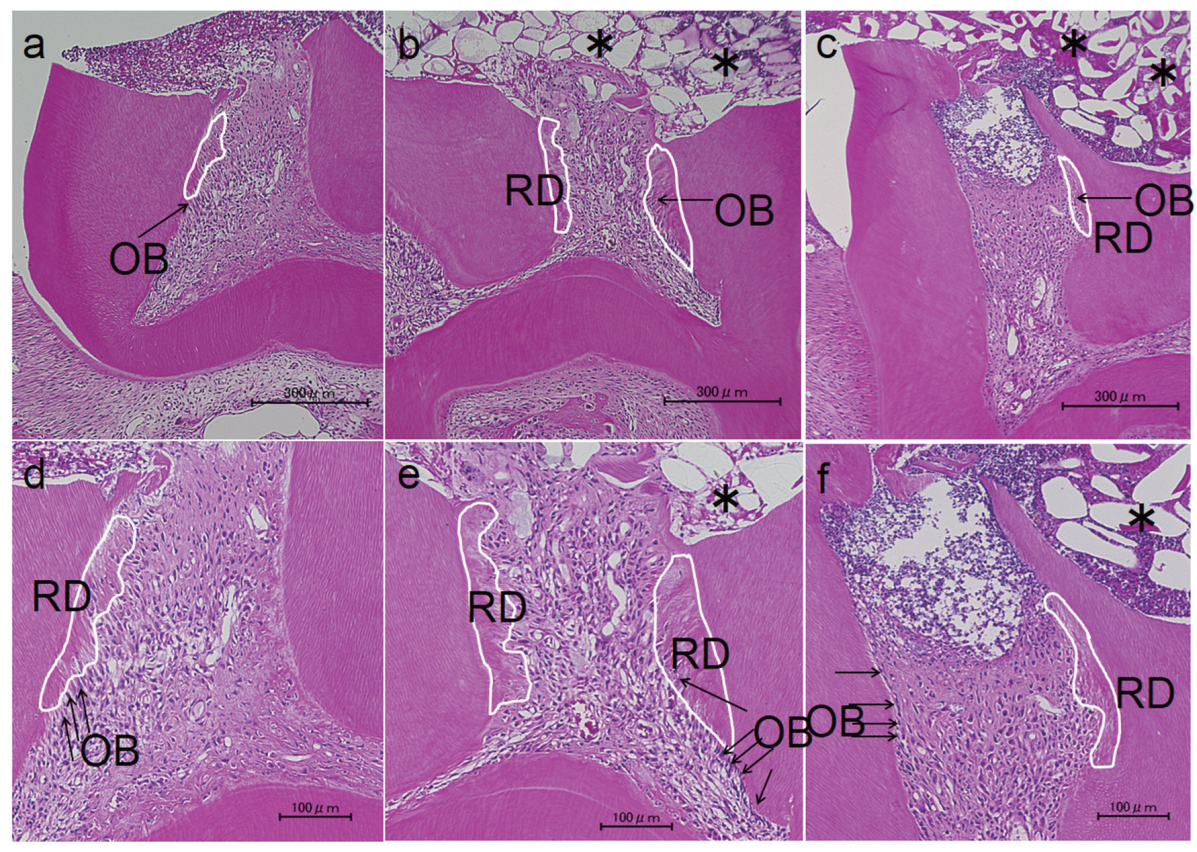

Fig. 7 Hematoxylin and eosin-stained sections of exposed dental pulp in rat molars at 1 week after surgery.

a, d: Control group, b, e: Nano-HAP group, c, f: nano-HAP/FGF2 group. RD: reparative dentin; asterisks: residual granules, OB: Odontoblast-like cells. Bars a, b, $c=300 \mu \mathrm{m}$, others $=100 \mu \mathrm{m}$.
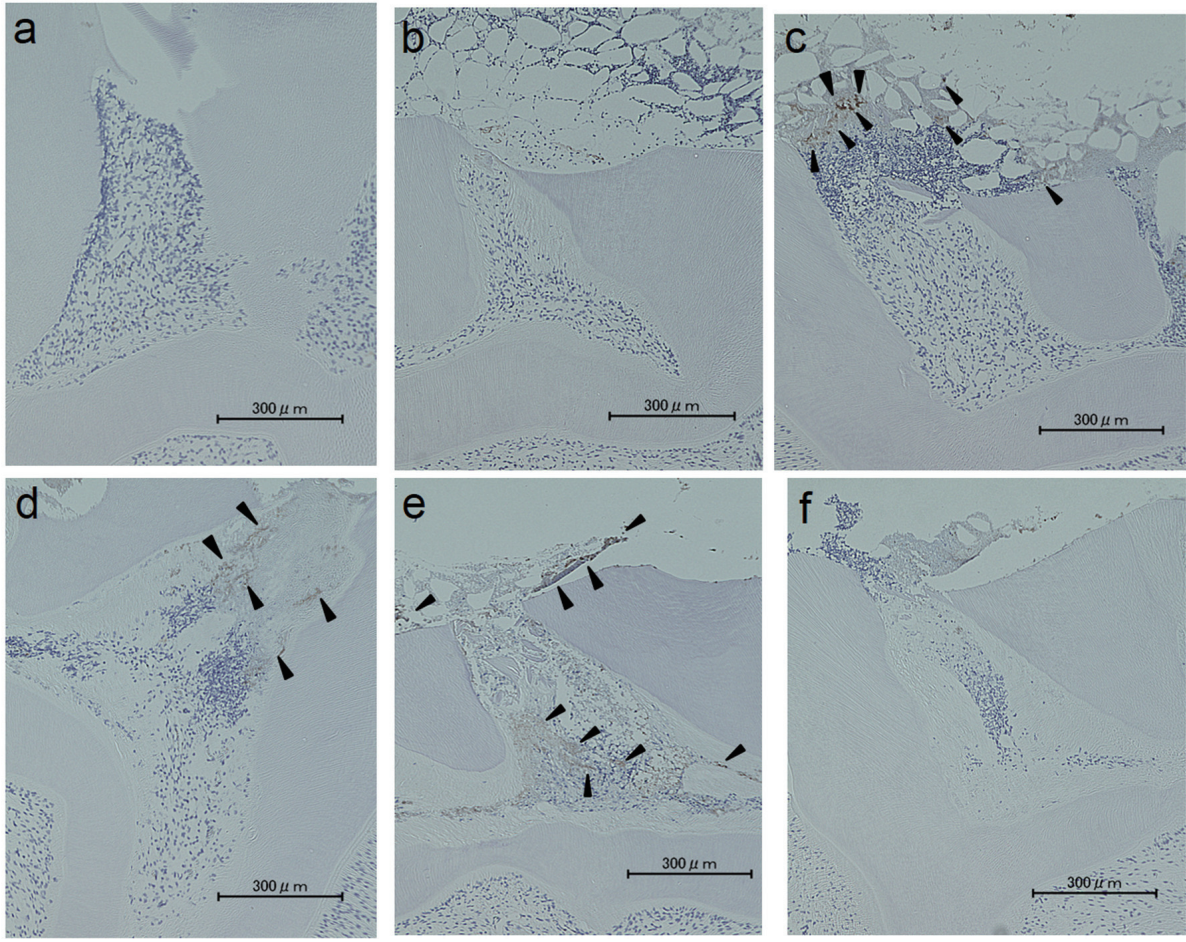

Fig. 8 Immunostaining of exposed dental pulp in rat molars.

a, d: Control group, b, e: Nano-HAP group, c, f: nano-HAP/FGF2 group, at 1 week after surgery $(a, b, c)$, or 2 weeks after surgery $(d, e, f)$. Black triangles: new vessels labeled for vWF. Bars $=300 \mu \mathrm{m}$. 

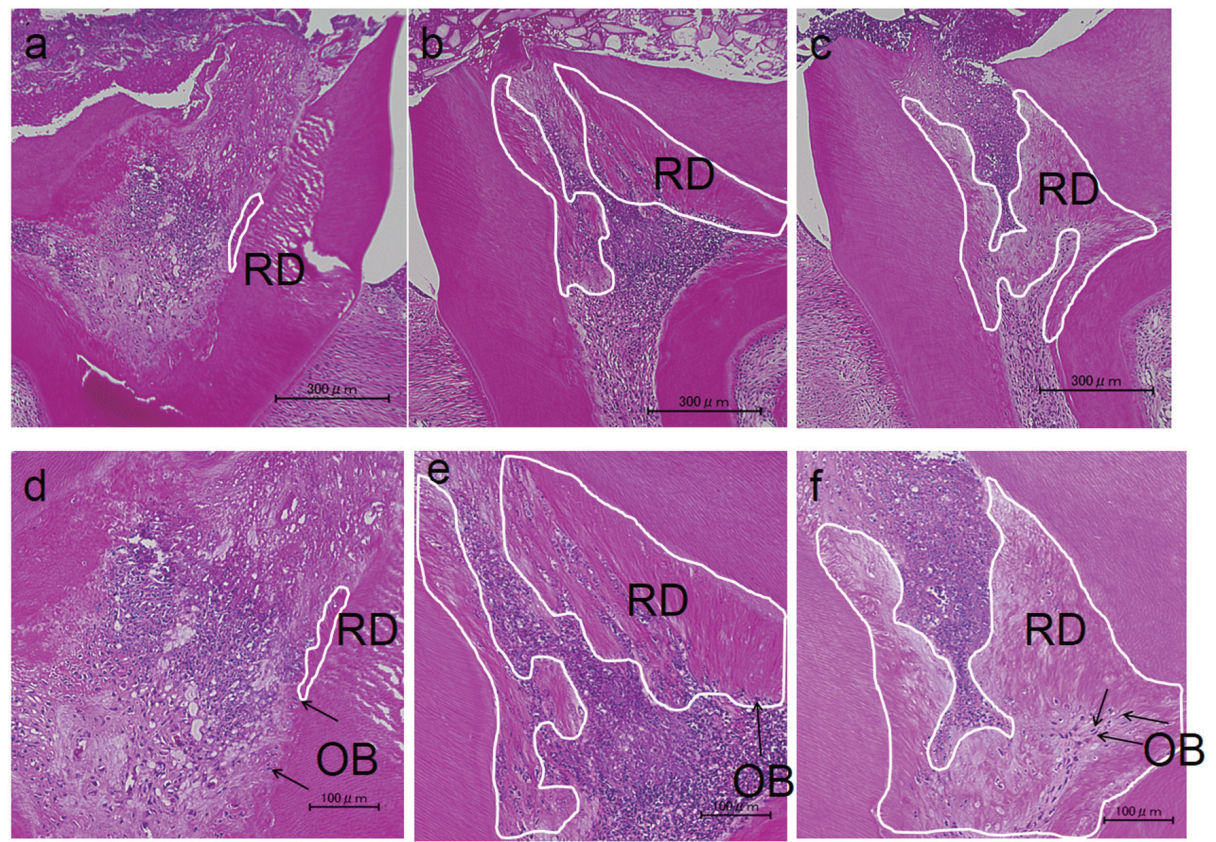

Fig. 9 Hematoxylin and eosin-stained sections of exposed dental pulp in rat molars at 2 weeks after surgery. a, d: Control group. b, e: Nano-HAP group. c, f: nanoHAP/FGF2 group. RD: reparative dentin; asterisks: residual granules, OB: Odontoblast-like cells. Bars a, b, c=300 $\mu \mathrm{m}$, others $=100 \mu \mathrm{m}$.

\section{DISCUSSION}

Rat dentition consists of two incisor teeth and three molar teeth, which are divided by a distinct diastema ${ }^{30}$. Odontoblast-like cells form typical reparative dentin after pulp exposure in murine as well as human molars ${ }^{31)}$. Removal of the roof of the pulp chamber from rat molar teeth and the vital pulp tissue in contact with the oral cavity results in an inflammatory reaction identical to that observed in humans ${ }^{30}$. Thus, rat molar teeth are a valid model for investigating the pulp tissue reaction after direct pulp capping, although the biological response process progresses faster in rats than in humans ${ }^{32}$.

The morphology of HAP nanoparticles depends on the precipitation conditions, such as the concentration of reactants, ionic strength, $\mathrm{pH}$, and temperature ${ }^{26,27)}$. The nano-HAP particles have nanosized roughness because of their nanoparticle morphology and also have nanosized pores between the nanoparticles (typical pore size, $8 \mathrm{~nm}{ }^{26,27,33)}$. In our study, XRD measurement showed a broad pattern of HAP. This suggests formation of low-crystallinity HAP, which has higher solubility than does well-crystallized HAP ${ }^{34}$. FT-IR indicated the substitution of carbonate ions in the phosphate positions of the HAP lattice ${ }^{35}$. The substitution of the carbonate ions may occur during the wet chemical process and/or the reaction with $\mathrm{CO}_{2}$ in air during drying ${ }^{36)}$ The $\mathrm{Ca} / \mathrm{P}$ atomic ratio of the synthesized powder, as measured by XPS, was 1.45 . The $\mathrm{Ca} / \mathrm{P}$ atomic ratio of nano-HAP synthesized using wet-state methods under relatively low temperatures is lower than that of the wellcrystallized stoichiometric HAP synthesized by solidstate methods ${ }^{27}$.

HAP nanoparticles have previously been investigated as a carrier for growth factors ${ }^{37,38}$. In the present study, XPS analysis showed that FGF2 bound to the nano-HAP particles. The unit cell of FGF2 has been reported to be $a=3.09 \mathrm{~nm}, b=3.34 \mathrm{~nm}, c=3.59 \mathrm{~nm}$, $\alpha=59.58, \beta=72.08$, and $\gamma=75.68^{39}$; thus, the molecular size of FGF2 was small compared to the pore size of the nano-HAP particles used in this study. Our previous study ${ }^{33}$ demonstrated that the rate of release of protein molecules, such as cytochrome $\mathrm{C}^{40)}(2.6 \times 3.2 \times 3.0 \mathrm{~nm})$, decreased with the decrease in pore size. This indicates that sustained release is caused by penetration of the solution containing FGF2 into the nanopores of the HAP granules followed by desorption of the FGF2 from the pore surfaces. It will be necessary to ascertain whether sustained release of FGF2 from the nano-HAP particles prepared in this study can be maintained in the longterm, in order to determine whether this material can be used as a pulp-capping agent that also acts as a scaffold for human growth factor proteins.

For the pulp exposures, pulpal inflammation is treated by a direct pulp-capping technique with $\mathrm{CH}$. This mechanism for repairing the dentin relies on the high alkalinity of $\mathrm{CH}$, which induces focal necrosis upon contacting the pulp, and subsequent formation of a dentine bridge between this layer and the underlying vital pulp ${ }^{1}$. Sena et al. reported that a slight 
inflammatory cell response was observed when octacalcium phosphate, which has a neutral $\mathrm{pH}$, was applied to the exposed dental pulp of rat molars. In our study, in the nano-HAP group, some infiltration of inflammatory cells was observed at the pulp exposure site, but no necrosis of the pulp was observed. Treatment with nano-HAP/FGF2 was consistently found to stimulate formation of a dentinal bridge, containing numerous dentinal tubules. The finding related to the FGF2 dose applied in this study is supported by the report of Ishimatsu et $a l .{ }^{411}$, who found that more calcified tissues were formed in the pulp when high doses (1.0 or $5.0 \mathrm{mg} / \mathrm{mL}$ ) of FGF2 were incorporated into the gelatin hydrogels used to repair dentin defects. On the other hand, Hu et al. ${ }^{4)}$ concluded that using TGF- $\beta 1$ as a pulp-capping medication enhanced reparative dentin formation in rat molars, while FGF2 did not. It is likely that application of the low doses ( $30 \mathrm{ng}$ ) of FGF2 used by $\mathrm{Hu}$ et al. ${ }^{4)}$ will not promote repair.

Our previous study ${ }^{42}$ demonstrated that FGF2 immobilized on alpha-tricalcium phosphate particles enhanced vascularization and could effectively reduce the time required to regenerate the periodontium in a canine model of two-walled periodontal defects. In the present study, we frequently observed ingrowth of vascular endothelial cells into the exposed pulp treated with FGF2 in the early stage (1 week after surgery), which then disappeared along with the appearance of a dentinal bridge-like structure in the late stage ( 2 weeks after surgery). We observed the appearance of a dentinal bridge-like structure at an earlier stage than that previously reported with FGF2 released from gelatin hydrogels ${ }^{41}$, and at a stage similar to that obtained by direct pulp-capping with TGF- $\beta 1^{4)}$. Thus, we speculate that the effect of FGF2 on blood vessel formation is important for formation of calcified tissues.

\section{CONCLUSIONS}

Stem cells, appropriate scaffolds, and growth factors are required to achieve tissue regeneration. In the present study, we used nano-HAP as a scaffold, FGF2 as a growth factor, and residual amputated pulp as a reservoir for pulp stem cells. We show that FGF2 released over the long-term from nano-HAP induced invasion of dental pulp cells and vessels, and thereby influenced the structure of calcified tissue regenerated in dentin defects. Further investigations should be performed to elucidate the mechanism by which nanoHAP/FGF2 contributes to calcified tissue formation.

\section{ACKNOWLEDGMENTS}

We thank Isumi TODA, Department of Anatomy, Osaka Dental University for supporting the animal experiment. This work was funded by Osaka Dental University Research Funds (18-01).

\section{CONFLICTS OF INTEREST}

The authors declare no conflicts of interest associated with this manuscript.

\section{REFERENCES}

1) Foreman P, Barnes I. A review of calcium hydroxide. Int Endod J 1990; 23: 283-297.

2) Gerstein H. Techniques in clinical endodontics 1983.

3) Spangberg L. Biocompatibility of restorative materials. Dental pulp: reactions to restorative materials in the presence or absence of infection 1982: 53-89.

4) $\mathrm{Hu}$ CC, Zhang C, Qian Q, Tatum NB. Reparative dentin formation in rat molars after direct pulp capping with growth factors. J Endod 1998; 24: 744-751.

5) Batouli S, Miura M, Brahim J, Tsutsui TW, Fisher LW, Gronthos S, et al. Comparison of stem-cell-mediated osteogenesis and dentinogenesis. J Dent Res 2003; 82: 976981.

6) Gronthos S, Brahim J, Li W, Fisher LW, Cherman N, Boyde A, et al. Stem cell properties of human dental pulp stem cells. J Dent Res 2002; 81: 531-535.

7) Gronthos S, Mankani M, Brahim J, Robey PG, Shi S. Postnatal human dental pulp stem cells (DPSCs) in vitro and in vivo. Proc Natl Acad Sci U S A 2000; 97: 13625-13630.

8) Laino G, D'Aquino R, Graziano A, Lanza V, Carinci F, Naro $\mathrm{F}$, et al. A new population of human adult dental pulp stem cells: A useful source of living autologous fibrous bone tissue (LAB). J Bone Miner Res 2005; 20: 1394-1402.

9) Nakashima M, Nagasawa H, Yamada Y, Reddi AH. Regulatory role of transforming growth factor- $\beta$, bone morphogenetic protein-2, and protein-4 on gene expression of extracellular matrix proteins and differentiation of dental pulp cells. Dev Biol 1994; 162: 18-28.

10) Shiba H, Fujita T, Doi N, Nakamura S, Nakanishi K, Takemoto $\mathrm{T}$, et al. Differential effects of various growth factors and cytokines on the syntheses of DNA, type I collagen, laminin, fibronectin, osteonectin/secreted protein, acidic and rich in cysteine (SPARC), and alkaline phosphatase by human pulp cells in culture. J Cell Physiol 1998; 174: 194-205.

11) Tsukamoto $Y$, Fukutani S, Shin-ike T, Kubota T, Sato S, Suzuki Y, et al. Mineralized nodule formation by cultures of human dental pulp-derived fibroblasts. Arch Oral Biol 1992; 37: 1045-1055.

12) Kim JC, Park JC, Kim SH, Im GI, Kim BS, Lee JB, et al. Treatment of FGF-2 on stem cells from inflamed dental pulp tissue from human deciduous teeth. Oral Dis 2014; 20: 191204.

13) Kim SG, Zhou J, Solomon C, Zheng Y, Suzuki T, Chen M, et al. Effects of growth factors on dental stem/progenitor cells. Dent Clin North Am 2012; 56: 563-575.

14) Osathanon $T$, Nowwarote $N$, Pavasant P. Basic fibroblast growth factor inhibits mineralization but induces neuronal differentiation by human dental pulp stem cells through a FGFR and PLC $\gamma$ signaling pathway. J Cell Biochem 2011; 112: 1807-1816.

15) Sagomonyants K, Kalajzic I, Maye P, Mina M. Enhanced dentinogenesis of pulp progenitors by early exposure to FGF2. J Dent Res 2015; 94: 1582-1590.

16) Chen L, Komasa S, Hashimoto Y, Hontsu S, Okazaki J. In vitro and in vivo osteogenic activity of titanium implants coated by pulsed laser deposition with a thin film of fluoridated hydroxyapatite. Int J Mol Sci 2018; 19: E1127.

17) Hashimoto Y, Kawashima M, Hatanaka R, Kusunoki M, Nishikawa H, Hontsu S, et al. Cytocompatibility of calcium phosphate coatings deposited by an ArF pulsed laser. J Mater Sci Mater Med 2007; 18: 1457-1464. 
18) Hashimoto Y, Nishikawa H, Kusunoki M, Li P, Hontsu S, et al. A novel membrane-type apatite scaffold engineered by pulsed laser ablation. Dent Mater J 2015; 34: 345-350.

19) Frank RM, Wiedemann P, Hemmerle J, Freymann M. Pulp capping with synthetic hydroxyapatite in human premolars. J Appl Biomater 1991; 2: 243-250.

20) Hayashi Y, Imai M, Yanagiguchi K, Viloria IL, Ikeda T. Hydroxyapatite applied as direct pulp capping medicine substitutes for osteodentin. J Endod 1999; 25: 225-229.

21) Appleford MR, Oh S, Oh N, Ong JL. In vivo study on hydroxyapatite scaffolds with trabecular architecture for bone repair. J Biomed Mater Res A 2009; 89: 1019-1027.

22) Balasundaram G, Sato M, Webster TJ. Using hydroxyapatite nanoparticles and decreased crystallinity to promote osteoblast adhesion similar to functionalizing with RGD. Biomaterials 2006; 27: 2798-2805.

23) Huang J, Best SM, Bonfield W, Brooks RA, Rushton N, Jayasinghe SN, et al. In vitro assessment of the biological response to nano-sozed hydroxyapatite. J Mater Sci Mater Med 2004; 15: 441-445.

24) Sun W, Chu C, Wang J, Zhao H. Comparison of periodontal ligament cells responses to dense and nanophase hydroxyapatite. J Mater Sci Mater Med 2007; 18: 677-683.

25) Webster TJ, Ergun C, Doremus RH, Siegel RW, Bizios R. Enhanced osteoclast-like cell functions on nanophase ceramics. Biomaterials 2001; 22: 1327-1333.

26) Okada M, Furuzono T. Low-temperature synthesis of nanoparticle-assembled, transparent, and low-crystallized hydroxyapatite blocks. J Colloid Interface Sci 2011; 360: 457462.

27) Okada M, Matsumoto T. Synthesis and modification of apatite nanoparticles for use in dental and medical applications. Jpn Dent Sci Rev 2015; 51: 85-95.

28) Fowler B. Infrared studies of apatites. I. Vibrational assignments for calcium, strontium, and barium hydroxyapatites utilizing isotopic substitution. Inorg Chem 1974; 13: 194-207.

29) Taylor MG, Parker SF, Simkiss K, Mitchell PCH. Bone mineral: Evidence for hydroxy groups by inelastic neutron scattering. Phys Chem Chem Phys 2001; 3: 1514-1517.

30) Dammaschke T. Rat molar teeth as a study model for direct pulp capping research in dentistry. Lab Anim 2010; 44: 1-6.
31) D'souza R, Bachman T, Baumgardner K, Butler W, Litz M. Characterization of cellular responses involved in reparative dentinogenesis in rat molars. J Dent Res 1995; 74: 702-709.

32) Muruzábal M, Erausquin J. Discussion of: methods and criteria in evaluation of periapical response. Int Dent J 1970; 20: 539-554.

33) Uehira M, Okada M, Takeda S, Matsumoto N. Preparation and characterization of low-crystallized hydroxyapatite nanoporous plates and granules. Appl Surf Sci 2013; 287: 195-202.

34) Fulmer MT, Ison IC, Hankermayer CR, Constantz BR, Ross J. Measurements of the solubilities and dissolution rates of several hydroxyapatites. Biomaterials 2002; 23: 751-755.

35) Emerson WH, Fischer EE. The infra-red absorption spectra of carbonate in calcified tissues. Arch Oral Biol 1962; 7: 671683.

36) Ishikawa K, Ishikawa Y, Kuwayama N. Preparation of carbonate-bearing hydroxyapatites and their sintering properties. Chem Express 1991; 6: 463-466.

37) Gorbunoff MJ, Timasheff SN. The interaction of proteins with hydroxyapatite: III. Mechanism. Anal Biochem 1984; 136: 440-445.

38) Matsumoto T, Okazaki M, Inoue M, Yamaguchi S, Kusunose $\mathrm{T}$, Toyonaga T, et al. Hydroxyapatite particles as a controlled release carrier of protein. Biomaterials 2004; 25: 3807-3812.

39) Eriksson AE, Cousens LS, Weaver LH, Matthews BW. Threedimensional structure of human basic fibroblast growth factor. Proc Natl Acad Sci 1991; 88: 3441-3445.

40) Zhang M, Wu Y, Feng X, He X, Chen L, Zhang Y. Fabrication of mesoporous silica-coated CNTs and application in sizeselective protein separation. J Mater Chem 2010; 20: 58355842 .

41) Ishimatsu H, Kitamura C, Morotomi T, Tabata $Y$, Nishihara $\mathrm{T}$, Chen KK, et al. Formation of dentinal bridge on surface of regenerated dental pulp in dentin defects by controlled release of fibroblast growth factor-2 from gelatin hydrogels. J Endod 2009; 35: 858-865.

42) Matsuse K, Hashimoto Y, Kakinoki S, Yamaoka T, Morita S. Periodontal regeneration induced by porous alpha-tricalcium phosphate with immobilized basic fibroblast growth factor in a canine model of 2 -wall periodontal defects. Med Mol Morphol 2018; 51: 48-56. 